\title{
HUBUNGAN JOB EMBEDDEDNESS DAN BUDAYA KOLEKTIVISME PADA KARYAWAN GENERASI X DAN Y DI PLTD SIANTAN, KALIMANTAN BARAT
}

\author{
Anjini Sutampi'), Aditya Nanda Priyatama', Selly Astriana ${ }^{3)}$ \\ Program Studi Psikologi Fakultas Kedokteran Universitas Sebelas Maret, Surakarta \\ 1)anjinisutampi@gmail.com, ${ }^{2)}$ adityanandapriyatama@gmail.com, \\ ${ }^{3)}$ sellyastriana13@gmail.com
}

\begin{abstract}
The company currently recognizes two types of workforce generations based on age, namely generation $X$ and generation $Y$. Both generations have different characteristics, one of them is job embeddedness. Job embeddedness rate was found the highest in an organization with collectivism. An organizational culture that is developed in various companies in Indonesia is the collectivism culture, one of them is in PLTD Siantan, Kalimantan Barat.This study aims to (1) find out the differences in the tendency of job embeddedness on generation $X$ and generation $Y$ employees in terms of collectivism culture, (2) find out the differences of job embeddedness tendency in generation $X$ and generation $Y$ employees; (3) find out the differences of collectivism culture on generation X employees and generation $Y$ in PLTD Siantan, Kalimantan Barat.This study uses 69 samples of PLTD Siantan employees. The instruments used are job embeddedness scale and collectivism culture scale. The anava result shows that there is a difference in the tendency of job embeddedness in employees of generation $X$ and generation $Y$ in terms of collectivism culture of PLTD Siantan, Kalimantan Barat. The result shows that there is a difference of job embeddedness on generation $X$ employees and generation $Y$ employees. There are also cultural differences collectivism in generation $X$ employees and generation $Y$ employees. This means that hypothesis 1, hypothesis 2, and hypothesis 3 are accepted.
\end{abstract}

Keywords:job embeddedness, collectivism culture, generation $X$ and generation

\begin{abstract}
ABSTRAK: Perusahaan saat ini mengenal dua jenis generasi tenaga kerja berdasarkan rentang usia, yaitu generasi $\mathrm{X}$ dan generasi $\mathrm{Y}$. Kedua generasi tersebut memiliki perbedaan karakteristik, salah satunya adalah job embeddedness. Tingkat job embeddedness ditemui paling tinggi pada organisasi dengan budaya kolektivisme. Budaya organisasi yang berkembang di berbagai perusahaan di Indonesia adalah budaya kolektivisme, salah satunya adalah PLTD Siantan, Kalimantan Barat. Penelitian ini bertujuan untuk (1) mengetahui perbedaan kecenderungan job embeddedness pada karyawan generasi X dan Y ditinjau dari budaya kolektivisme, (2) Mengetahui perbedaan kecenderungan job embeddedness pada karyawan generasi X dan Y, (3) Mengetahui perbedaan budaya kolektivisme pada karyawan generasi X dan Y PLTD Siantan, Kalimantan Barat. Penelitian ini menggunakan seluruh anggota populasi sebanyak 69 karyawan PLT Siantan. Instrumen yang digunakan adalah skala job embeddedness, dan budaya kolektivisme. Berdasarkan hasil anava, menunjukkan perbedaan kecenderungan job embeddedness pada karyawan generasi X dan generasi Y ditinjau dari budaya kolektivisme PLTD Siantan, Kalimantan Barat. Berdasarkan hasil analisis perbedaan rerata menunjukkan perbedaan job embeddedness pada karyawan generasi $\mathrm{X}$ dan karyawan generasi Y. Selain itu, terdapat juga perbedaan budaya kolektivisme pada karyawan generasi X dan karyawan generasi Y. Hal ini menjelaskan bahwa hipotesis penelitian 1, 2, dan 3 diterima.
\end{abstract}

Kata kunci: job embeddedness, budaya kolektivisme, generasi X dan Y

\section{PENDAHULUAN}

Leo Kanner pada tahun 1943 Dewasa ini, tenaga kerja di Indonesia mengalami peningkatan jumlah dari hari ke hari. Hal ini sesuai dengan data yang dihimpun dari Sekretariat Kabinet (2017) bahwa tenaga kerja di Indonesia mengalami peningkatan, Februari 2017 tercatat sebanyak 124,54 juta orang, atau naik sebanyak 6,13 juta orang dibandingkan dengan keadaan Agustus 2016. Jumlah tenaga kerja tersebut berasal dari berbagai rentang usia. Dunia kerja saat ini mengenal 
empat jenis generasi tenaga kerja berdasarkan rentang usia, diantaranya yaitu generasi tradisional, baby boomer, generasi $\mathrm{X}$ dan generasi Y (Tolbize, 2008). Generasi tradisional adalah generasi tertua di tempat kerja dan mayoritas telah pensiun karena generasi ini adalah generasi yang lahir di era sebelum tahun 1945 (Anick, 2008). Generasi selanjutnya adalah generasi yang disebut sebagai generasi baby boomer, yaitu generasi yang lahir dari mulai tahun 1946 sampai dengan tahun 1964. Setelah baby boomer, terdapat generasi $\mathrm{X}$ dengan kriteria tahun kelahiran antara 1965 sampai 1980. Terakhir adalah generasi yang disebut sebagai generasi Y, yaitu individu yang lahir dari tahun 1981 sampai 2000. (Gursoy, Dogan, Qing-Chi \& Karadag, 2013).

Berdasarkan usia karyawan yang telah dipaparkan pada penjelasan sebelumnya, dapat terlihat bahwa lima sampai dengan sepuluh tahun mendatang, perusahaan akan dikuasai oleh karyawan dari kedua generasi terakhir, yaitu generasi $\mathrm{X}$ dan generasi $\mathrm{Y}$. Generasi pertama yaitu generasi tradisional memang sudah tidak memiliki eksistensi di perusahaan, sementara generasi baby boomer akan mulai digantikan dengan generasi setelahnya karena masa pensiun. Berkaitan dengan keadaan tersebut, maka dapat disimpulkan bahwa keberadaan karyawan yang paling representatif dengan keadaan perusahaan di Indonesia saat ini hingga beberapa periode ke depan adalah generasi $\mathrm{X}$ dan Y.

Berbagai penelitian menunjukkan bahwa generasi $\mathrm{X}$ dan $\mathrm{Y}$ memiliki perbedaan dalam berbagai hal. Lancaster dan Stillman (2002) menjelaskan bahwa generasi $X$ merupakan generasi yang memiliki sifat cenderung menyadari adanya keragaman dan berpikir global, ingin menyeimbangkan antara pekerjaan dengan kehidupan, menggunakan pendekatan praktis dalam bekerja, serta berkeinginan untuk bersenang-senang dalam bekerja, sementara generasi $\mathrm{Y}$ memiliki sifat optimisme yang tinggi, fokus pada prestasi, serta memiliki kepercayaan diri yang tinggi.

Fatimah, Dharmawan, Sunarti, dan
Affandi (2015) menjelaskan pula bahwa Generasi Y mempunyai orientasi untuk bergerak dengan lebih cepat dan kreatif, namun tidak sabar dalam banyak situasi, serta berkecenderungan untuk menuntut. Berbeda dengan generasi $\mathrm{Y}$, sementara generasi $\mathrm{X}$ memiliki kecenderungan jiwa berwirausaha yang kuat dan memahami teknologi. Selain itu, penelitian yang dilakukan oleh Oktariani, Hubeis dan Sukandar (2017) menjelaskan bahwa generasi $\mathrm{X}$ dan generasi $\mathrm{Y}$ memiliki perbedaan dari segi komitmen kerja disebabkan oleh karakteristik yang dimiliki oleh masing-masing generasi, Generasi $\mathrm{X}$ cenderung lebih memiliki loyalitas yang tinggi serta tidak memiliki sifat individualisme dalam bekerja, berkebalikan dengan generasi Y. Penelitian tersebut menghasilkan temuan bahwa generasi $\mathrm{X}$ memiliki tingkat komitmen yang lebih tinggi dibandingkan dengan komitmen yang dimiliki oleh generasi $\mathrm{Y}$.

Andrea dan Machova (dalam Andrea, Gabriella \& Timea, 2016) menjelaskan pula bahwa generasi X lebih menyukai hubungan sosial secara langsung serta hubungan sosial secara virtual, sementara generasi $\mathrm{Y}$ lebih menunjukkan gejala konsistensi menyukai hubungan sosial secara virtual. Selain itu, generasi X juga memiliki tujuan utama mencapai posisi yang aman dalam sebuah perusahaan, sedangkan generasi $\mathrm{Y}$ lebih memiliki orientasi akan persaingan dalam memperebutkan posisi pemimpin atau atasan. Generasi X juga lebih menunjukkan kerja keras serta keingintahuan yang tinggi dalam melakukan suatu tugas, sementara generasi $\mathrm{Y}$ cenderung fleksibel dalam menghadapi pekerjaan dan pengetahuan yang luas terhadap banyak hal, namun lebih dangkal. Selanjutnya, generasi X memiliki perasaan taat terhadap aturan yang berlaku, namun sebaliknya, generasi $\mathrm{Y}$ adalah generasi yang lebih mencintai kebebasan.

Generasi $\mathrm{X}$ dan $\mathrm{Y}$ memiliki perbedaan pula dalam segi kelekatan dalam organisasi (job embeddedness). Hal ini terbukti dengan adanya penelitian yang dilakukan oleh Pardinata dan Respati (2014) berkaitan dengan perbedaan job 
embeddedness antara generasi $\mathrm{X}$ dan $\mathrm{Y}$. Penelitian tersebut menghasilkan temuan berupa, terdapat perbedaan yang signifikan antara kedua generasi tersebut. Hasil lebih lanjut menerangkan bahwa generasi $\mathrm{X}$ memiliki kecocokkan yang lebih besar berkaitan dengan pekerjaannya dalam organisasi dibandingkan dengan generasi Y. Selaras dengan hasil tersebut, generasi $\mathrm{X}$ juga memiliki persepsi akan pengorbanan yang harus mereka lakukan ketika meninggalkan pekerjaannya lebih tinggi daripada generasi Y.

Penelitian serupa juga dilakukan oleh Karunia (2015) berkaitan dengan perbedaan generasi $\mathrm{X}$ dan $\mathrm{Y}$ ditinjau dari job embeddedness. Penelitian ini menjelaskan bahwa intensi turnover generasi Y lebih tinggi daripada generasi $\mathrm{X}$. Selain itu, penelitian ini juga menerangkan bahwa intensi turnover dipengaruhi oleh faktor job embeddedness. Hal ini mengindikasikan bahwa job embeddedness generasi X lebih tinggi daripada generasi $\mathrm{Y}$. Perbedaan tersebut terjadi karena generasi $\mathrm{X}$ lebih merasakan kecocokan terhadap pekerjaannya dibandingkan dengan generasi Y.

Berdasarkan penjelasan di atas, job embedddedness merupakan suatu hal yang sangat krusial dalam menentukan terjadinya turnover dalam perusahaan. Qalbi, Jufri, dan Indahari (2016) dalam penelitiannya membenarkan bahwa salah satu faktor yang mempengaruhi turnover ialah keikatan organisasi (job embeddedness). Karyawan dengan tingkat job embeddedness yang tinggi akan memiliki perasaan bahwa dirinya cocok dengan pekerjaan yang ia tekuni saat ini, serta mengalami perasaan bahwa akan sangat merugi apabila dirinya meninggalkan pekerjaan tersebut (Fitriyani, 2013).

Selain memprediksi intensi keluarmasuknya karyawan dalam perusahaan, Nguyen (2010) juga menjelaskan melalui studi pustaka yang ia pelajari bahwa job embeddedness merupakan konstruksi yang sangat penting dalam memprediksi hal-hal krusial di dalam sebuah organisasi seperti ketidakhadiran, prestasi kerja, dan perilaku kewarganegaraan. Job embeddedness dapat pula meningkatkan produktivitas kerja karyawan yang berkontribusi baik pada pencapaian tujuan perusahaan (Fitriyani, 2013). Pemaparan di atas menunjukkan bahwa tingginya tingkat embedded atau kelekatan pada karyawan di sebuah perusahaan dapat memberikan berbagai dampak positif bagi keberjalanan perusahaan tersebut.

Tingginya tingkat job embeddedness pada karyawan di tempat kerja dapat pula dipengaruhi oleh budaya organisasi (Pardinata, dkk, 2014). Sedikitnya, terdapat dua jenis budaya organisasi yang umumnya digunakan oleh perusahaan, yaitu budaya kolektivisme dan budaya individualisme (Hofstede dalam Bochner, 1994). Kedua budaya ini dipisahkan berdasarkan rasa kepemilikan karyawan pada perusahaan. Budaya individualisme lebih melihat pada bagaimana diri seseorang dipisahkan dari orang lain, sementara budaya kolektivisme lebih menekankan pada peleburan identitas diri karyawan pada organisasi dimana mereka bekerja dan terhubung dengan orang-orang di lingkungan kerja tersebut (Bochner, 1994).

Penelitian yang dilakukan oleh Nafei (2015) menunjukkan bahwa job embeddedness berpengaruh secara signifikan baik pada negara dengan budaya kolektivisme maupun negara dengan budaya individualisme. Artinya, negara dengan budaya kolektivisme maupun individualisme sama-sama menunjukkan adanya job embeddedness. Meskipun begitu, job embeddedness pada negara dengan budaya kolektivisme menunjukkan hasil yang lebih signifikan. Hal tersebut dikarenakan, orang-orang dengan budaya kolektivisme akan lebih memiliki kebersamaan yang memunculkan faktorfaktor pembentuk job embeddedness. Indikasinya adalah, ketika sebuah tempat menggunakan budaya kolektivisme, maka embeddedness atau rasa kelekatan terhadap suatu tempat juga akan semakin besar.

PT PLN (Persero) adalah salah satu perusahaan Badan Usaha Milik Negara (BUMN) penyedia layanan jasa energi listrik di Indonesia (Febriana, 2016). PT 
PLN (Persero) sendiri memiliki fungsi krusial dalam distribusi energi listrik ke berbagai wilayah di seluruh penjuru negeri. Demi menunjang fungsi tersebut, PT PLN (Persero) dibagi menjadi unit-unit induk yang tersebar ke setiap daerah, salah satunya adalah Sektor Pembangkitan Kapuas, Kalimantan Barat. Unit ini terdiri dari 4 sub-unit yang terdiri dari karyawan dengan berbagai rentang usia dan spesifikasi pekerjaan. Salah satu dari subunit PLN adalah PLTD Siantan. Hasil wawancara dengan salah satu karyawan menujukkan bahwa PLTD Siantan merupakan sektor industri yang memiliki tingkat turnover rendah. Artinya, angka keluar masuknya karyawan dalam perusahaan termasuk rendah. Hal tersebut terjadi karena karyawan memiliki embeddedness yang cukup baik. Job embeddedness tersebut, menurut sumber yang sama, dapat terjadi karena karyawan PLTD Siantan, Kalimantan Barat memiliki ikatan kelompok yang kuat dengan perusahaan. Budaya inilah yang dimaksud budaya kolektivisme, dimana norma yang dianut secara seragam oleh karyawannya dan menjadikan mereka bergantung pada kelompok dalam melakukan aktivitasaktivitas dalam pekerjaannya. Selain itu, jenis pekerjaan di PLTD Siantan, Kalimantan Barat yang mayoritas membutuhkan koordinasi antar karyawan membuat masing-masing dari mereka memiliki kesempatan dan kebutuhan untuk mengaplikasikan budaya kolektivisme dalam organisasi.

Karyawan lainnya menjelaskan dalam sesi wawancara yang berbeda bahwa PLTD Siantan, Kalimantan Barat merasakan perbedaan tingkat embeddedness antara apa yang mereka sebut sebagai generasi tua (generasi $\mathrm{X}$ ) dengan generasi muda (generasi Y). Mereka memiliki pandangan bahwa generasi $X$ memiliki kelekatan yang lebih tinggi pada pekerjaan, serta mendalami nilai-nilai perusahaan lebih kuat dibandingkan dengan generasi di bawahnya, yaitu generasi Y. Hal tersebutlah yang membuat peneliti memiliki ketertarikan untuk mengadakan penelitian di PLTD Siantan, Kalimantan Barat.
Job embeddedness merupakan hal yang penting dan perlu untuk dilihat hubungannya dengan berbagai faktor di Indonesia. Job embeddedness juga merupakan temuan yang relatif baru dan apabila diteliti lebih dalam akan menghasilkan manfaat yang besar untuk menentukan bagaimana karyawan berperilaku (Nguyen, 2010). Besich (2005) menekankan pula bahwa penelitian empiris mengenai job embeddedness terhadap populasi atau budaya kerja yang berbeda merupakan hal yang baru. Fatimah, dkk (2015) melakukan penelitian dengan hasil bahwa budaya organisasi memiliki perbedaan yang signifikan dengan nilai pada generasi $\mathrm{X}$ lebih besar dari generasi $\mathrm{Y}$. Hal ini terjadi karena Budaya yang akan peneliti jadikan konsentrasi utama, adalah budaya kolektivisme, yaitu budaya yang digunakan oleh PLTD Siantan, Kalimantan Barat dalam kaitannya dengan kerjasama tim yang diusung sebagai salah satu budaya organisasi. Sementara pengambilan sampel pada generasi X dan Y adalah karena kedua generasi tersebut adalah generasi yang akan memiliki eksistensi paling besar untuk beberapa tahun ke depan. Selain itu, perbedaan job embeddedness antara generasi $\mathrm{X}$ dan generasi $\mathrm{Y}$ yang telah dipaparkan dalam berbagai teori membuat peneliti tertarik untuk membuktikan apakah perbedaan antara kedua generasi berkaitan dengan job embeddedness dalam penelitian terdahulu memang berlaku sama pada setiap kondisi serta situasi.

\section{Job Embeddedness}

Job embeddedness adalah sebuah konstruk yang di dalamnya terdapat dua hal utama, yaitu hal yang bersifat organisasi dan non-organisasi, kedua hal inilah yang menyebabkan seorang individu bertahan pada organisasi atau perusahaannya (Pane, 2016). Ng dan Feldman (2009) juga mendukung pendapat tersebut dengan menjelaskan bahwa job embeddedness adalah suatu istilah yang membuat individu tetap bertahan pada tempatnya di dalam suatu situasi dan membuatnya sulit untuk keluar dari organisasi. Secara lebih singkat, Granovetter (2010) memaparkan bahwa job 
embeddedness merupakan suatu konsep baru yang digunakan untuk melihat seberapa banyak individu terjerat dalam perusahaan tepatnya bekerja.

Mitchell, Holtom, Lee dan Erez (2001) mendefinisikan job embeddedness sebagai totalitas kekuatan yang menghalangi seseorang untuk meninggalkan pekerjaannya saat ini. Mereka pun menjelaskan bahwa definisi job embeddedness memiliki tiga penjabaran lain yang lebih luas. Pertama adalah berkaitan dengan hubungan seseorang terhadap orang lain, tim serta grup mereka. Kedua adalah berkaitan dengan persepsi dari kecocokkan seseorang dengan pekerjaannya, organisasi, serta komunitas. Sementara yang terakhir adalah apa yang mereka pikir akan mereka korbankan, seberapa banyak dan seberapa jauh pengorbanan tersebut apabila mereka meninggalkan pekerjaan mereka.

Job embeddedness memiliki arti berupa sebuah keterikatan karyawan dalam organisasi melalui jaringan sosial, yang dibagi menjadi dua, yaitu kepercayaan dan kohesi. Keseluruhan dari faktor yang mengikatkan karyawan dalam pekerjaan yang mereka lakukan disebut juga sebagai job embeddedness. Keterikatan tersebut dapat terjadi jika terdapat kemiripan antara nilai dari pekerjaan yang dilakukan dengan nilai yang individu telah individu bahwa. (Qalbi dkk, 2016)

Berdasarkan pendapat-pendapat yang dikemukakan para ahli, dapat disimpulkan bahwa job embeddedness adalah jejaring yang menyebabkan individu, khususnya karyawan dalam suatu perusahaan untuk memilih bertahan dalam pekerjaannya karena berbagai faktor yang mendukungnya untuk bertahan berupa kecocokan pekerjaan, hubungan sosial serta banyaknya hal yang harus dikorbankan apabila karyawan keluar dari sebuah perusahaan.

\section{Budaya kolektivisme}

Hofstede, Hofstede dan Minkov (2010) membagi kedua budaya yang saling bertentangan dalam seting tempat kerja, yaitu budaya individualisme dan budaya kolektivisme. Penelitian yang dilakukan oleh Nguyen (2010) menunjukkan bahwa budaya kolektivisme memiliki pengaruh yang lebih besar dalam menciptakan job embeddedness.

Hofstede (2010) menambahkan bahwa kolektivisme merupakan keadaan anggota masyarakat yang memiliki ikatan kelompok kuat serta terikat sepanjang kehidupan mereka untuk saling menjaga satu sama lain. Masyarakat dengan tingkat kolektivisme yang tinggi biasanya ditunjukkan dengan sikap dan rasa empati yang tinggi terhadap individu lain dalam kelompok yang sama dan mengharapkan adanya kepedulian yang ditunjukkan kelompok kepada dirinya.

Budaya Kolektivisme didefinisikan sebagai internalisasi karyawan tentang nilai, norma, kebiasaan kelompok yang diterima, kemudian dijadikan aturan serta budaya kerja sehari-hari dalam perilaku kerja, terutama dalam memecahkan masalah yang dihadapi (Septarini \& Yuwono, 2003). Masyarakat dengan budaya kolektivisme memiliki pengertian berupa individu terbaur dengan kuat, bersatu didalam kelompok, yang mana sepanjang hidup anggota masyarakat memiliki kesetiaan yang tidak diragukan lagi (Xuyen, Utari, \& Rahmanto, 2016).

Berdasarkan penjabaran sebelumnya, dapat ditarik kesimpulan bahwa budaya kolektivisme dalam perusahaan merupakan suatu kepercayaan yang dipegang anggotanya, bahwa mereka meyakini pembauran diri dengan organisasi adalah hal utama, mereka juga melakukan usaha-usaha untuk kepentingan organisasi daripada sekedar kepentingan pribadi.

\section{Generasi X dan Y}

Generasi $\mathrm{X}$ adalah orang-orang yang memiliki tahun kelahiran antara tahun antara 1965 sampai 1980. Mereka adalah generasi yang tumbuh dan berkembang pada awal-awal tahun perkembangan teknologi sedang menggeliat. Sementara Generasi Y atau biasa pula disebut sebagai generasi milenial adalah individu yang lahir dari tahun 1981 sampai 2000 (Gursoy dkk, 2013). 


\section{METODE PENELITIAN}

Populasi dalam penelitian ini adalah seluruh karyawan di sub-unit PLTD Siantan. Populasi dalam penelitian ini berjumlah 69 orang. Penelitian ini menggunakan studi populasi, yaitu pengambilan sampel dari keseluruhan anggota populasi.

Pengumpulan data dalam penelitian ini dengan menyebarkan kuesioner, keseluruhan kuesioner tersebut digunakan dalam analisis data. Penelitian ini menggunakan metode pengumpulan data kuantitatif dengan menggunakan duaskala yaitu skala job embeddedness, dan skala budaya kolektivisme. Skala job embeddedness yang digunakan dalam penelitian ini berdasarkan pada skala yang dibuat oleh Pane (2016) berdasarkan aspek yang disusun oleh Mitchell (2001). Aspek tersebut terdiri dari fit, link dan sacrifice. Budaya kolektivisme pada penelitian ini akan diukur melalui skala yang disusun berdasarkan aspek berdasarkan pada aspek yang dibuat oleh Hofstede (dalam Septarini dan Yuwono, 2003). Aspeknya antara lain adalah hubungan sub-ordinat dan ordinat, hubungan antara individu dengan kelompok, pengambilan keputusan, harmonisasi, komunikasi, dan sistem manajemen.

Validitas skala dalam penelitian ini menggunakan corrected item total correlation dengan menggugurkan aitem skala yang memiliki koefisien korelasi di bawah 0,3. Uji reliabilitas menggunakan formula Alpha Cronbach. Berdasarkan hasil uji validitas dan reliabilitas skala job embeddedness terdapat 18 aitem valid dengan koefisien reliabilitas sebesar 0,846, sementara pada skala budaya kolektivisme terdapat 24 aitem valid dengan koefisien reliabilitas sebesar 0,898.

\section{HASIL DAN PEMBAHASAN}

$$
\text { Hasil pengujian Anova }
$$
menjelaskan bahwa nilai signifikansi sebesar $0,000(\mathrm{p}<0,05)$ dan nilai $\mathrm{F}$ hitung sebesar 24,501. F hitung > F tabel yaitu
$24,501>7,03$. Artinya, terdapat perbedaan kecenderungan job embeddedness pada karyawan generasi $\mathrm{X}$ dan generasi $\mathrm{Y}$ ditinjau dari budaya kolektivisme.

Hasil uji independent t-test memperlihatkan nilai signifikansi (Sig. 2tailed) sebesar 0,000 dan bahwa t hitung sebesar 5,008 dan t tabel $=1,996$ sehingga $\mathrm{t}$ hitung $>\mathrm{t}$ tabel $(5,008>1,996)$. Hal ini menunjukkan bahwa terdapat perbedaan job embeddedness pada karyawan generasi $\mathrm{X}$ dan karyawan generasi $\mathrm{Y}$.

Tabel 1 menunjukkan rata-rata job embeddedness pada karyawan generasi $\mathrm{X}$ yaitu 57,50, sementara nilai rata-rata job embeddedness pada generasi $\mathrm{Y}$ yaitu 52,28 . Hal ini menunjukkan bahwa nilai rata-rata job embeddedness pada karyawan generasi $\mathrm{X}$ lebih tinggi dari pada karyawan generasi $\mathrm{Y}$ dengan perbedaan rata-rata 5,22 .

Tabel 1. Deskripsi statistik Job Embeddedness karyawan generasi $\mathrm{X}$ dan generasi Y

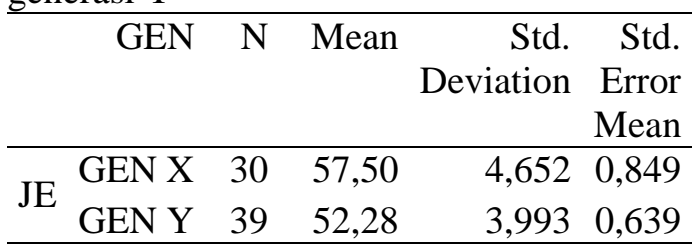

Hasil uji t menunjukkan bahwa nilai signifikansi sebesar 0,000 (sig 2tailed $<0,05$ ). Selain itu, nilai $t$ hitung sebesar 5,384 dan diperoleh $\mathrm{t}$ tabel $=1,996$ sehingga $t$ hitung $>t$ tabel. Artinya adalah terdapat perbedaan budaya kolektivisme pada karyawan generasi $\mathrm{X}$ dan karyawan generasi Y.

Berkaitan dengan perbedaan budaya kolektivisme antara kedua generasi dapat dijelaskan melalui tabel 2. Nilai ratarata budaya kolektivisme pada karyawan generasi $X$ yaitu 82,53, sementara nilai ratarata budaya kolektivisme pada generasi $\mathrm{Y}$ yaitu 74,69. Hal ini menunjukkan bahwa nilai rata-rata budaya kolektivisme pada karyawan generasi $\mathrm{X}$ lebih tinggi dari pada karyawan generasi $\mathrm{Y}$ dengan perbedaan rata-rata 7,84 . 
Tabel 2. Deskripsi statistik budaya kolektivisme karyawan generasi $\mathrm{X}$ dan generasi Y

\begin{tabular}{rrrr}
\hline & GEN & N & Mean \\
\hline BK & GEN X & 30 & 82,53 \\
& GEN Y & 39 & 74,69 \\
\hline
\end{tabular}

Hasil uji hipotesis pada penelitian ini menunjukkan bahwa terdapat perbedaaan job embeddedness antara karyawan generasi $\mathrm{X}$ dan karyawan generasi $\mathrm{Y}$ ditinjau dari budaya kolektivisme. Hal ini ditunjukan dari nilai signifikansi $0,000 \quad(\mathrm{p}<0,05)$ dan nilai $\mathrm{F}$ hitung pada budaya kolektivisme sebesar 24,501 (Fhit>Ftabel yaitu 24,501 > 7,03). Nafei (2015) memberikan penjelasan bahwa karyawan dengan budaya kolektivisme yang cenderung tinggi akan memunculkan kebersamaan bersama anggota kelompoknya. Hal ini terjadi karena budaya kolektivisme menekankan pada kepentingan menjaga harmoni dalam kelompok. Salah satu usahanya adalah dengan memunculkan kebersamaan antara karyawan PLTD Siantan. Kebersamaan yang telah muncul dan mengakar ini akan membentuk faktor terciptanya job embeddedness. Selain itu, generasi X lebih berorientasi pada kelompoknya dalam melakukan berbagai tugas, dalam hal ini adalah pekerjaannya. Berbeda dengan generasi $\mathrm{X}$, generasi $\mathrm{Y}$ cenderung lebih berfokus pada diri sendiri dalam bekerja. Hal inilah yang menyebabkan tingkat budaya kolektivisme generasi $\mathrm{X}$ lebih tinggi daripada generasi Y.

Selain itu, terdapat perbedaan job embeddedness pada karyawan generasi $\mathrm{X}$ dan karyawan generasi Y. Hal ini didasarkan pada uji independent sample $t$ yang dipermudah dengan menggunakan bantuan dari SPSS for windows yang menunjukkan $\mathrm{t}$ hitung $>\mathrm{t}$ tabel $(3,258>1,996)$, dengan nilai sig (2-tailed) sebesar 0,002 (sig 2-tailed<0,05). Nilai rata-rata job embeddedness pada karyawan generasi $X$ yaitu 57,50 dan nilai rata-rata job embeddedness pada generasi Y yaitu 52,28 sehingga nilai rata-rata job embeddedness pada karyawan generasi $\mathrm{X}$ lebih tinggi dari pada karyawan generasi $\mathrm{Y}$ dengan perbedaan rata-rata 5,22.

Karyawan generasi $X$ di PLTD Siantan, Kalimantan Barat memiliki tingkat job embeddedness yang lebih tinggi dibandingkan dengan karyawan generasi Y. Oktariani, Hubeis dan Sukandar (2017) menjelaskan bahwa generasi $\mathrm{X}$ memiliki komitmen dalam bekerja yang lebih baik dibandingkan dengan generasi Y. Hal ini cukup menjelaskan hasil penelitian yang menunjukkan bahwa komitmen untuk tetap bertahan dalam pekerjaan yang telah diemban oleh karyawan memiliki hubungan yang berbanding lurus dengan job embeddedness. Implikasinya adalah, ketika karyawan generasi X memiliki komitmen yang cenderung tinggi, maka rasa embedded yang ia miliki juga akan cenderung tinggi.

Pardinata dan Respati (2014) menjelaskan penyebab mengenai lebih tingginya tingkat job embeddedness pada generasi $\mathrm{X}$ dibandingkan dengan generasi Y. Hal ini dapat disebabkan karena generasi Y cenderung memiliki rasa bahwa tidak ada pengorbanan terlalu besar yang akan mereka akan hadapi setelah meninggalkan pekerjaannya. Sementara di sisi lain, generasi $\mathrm{X}$ lebih memiliki pertimbangan akan kondisi yang akan mucul ketika mereka harus memutuskan untuk keluar dari pekerjaan yang dimilikinya.

Hasil penelitian ini juga menjelaskan bahwa terdapat perbedaan tingkat budaya kolektivisme antara karyawan generasi $\mathrm{X}$ dan generasi Y. Keluaran dari program SPSS versi 23.0 for windows dengan menggunakan penghitungan uji Independent sample t test, memperoleh nilai $\mathrm{t}$ hitung $>\mathrm{t}$ tabel $(2,906>1,996)$ dengan signifikansi (2-tailed) sebesar $0,005<0,05$ maka $\mathrm{H}_{0}$ ditolak dan $\mathrm{H}_{\mathrm{a}}$ diterima. Nilai ratarata job embeddedness pada karyawan generasi $X$ yaitu 57,50 dan nilai rata-rata job embeddedness pada generasi $\mathrm{Y}$ yaitu 52,28 sehingga nilai rata-rata job embeddedness pada karyawan generasi $\mathrm{X}$ lebih tinggi dari pada karyawan generasi $\mathrm{Y}$ dengan perbedaan rata-rata 5,22.

Temuan tersebut sejalan dengan pendapat Andrea dan Machova (dalam 
Andrea, Gabriella \& Timea, 2016) tentang generasi $\mathrm{X}$ yang lebih menyukai hubungan sosial secara langsung. Hubungan sosial yang dibentuk oleh karyawan generasi $\mathrm{X}$ ini merupakan salah satu aspek yang dimiliki oleh variabel budaya kolektivisme berupa komunikasi. Komunikasi yang terbentuk dari hubungan sosial dapat menyebabkan internalisasi budaya kolektivisme secara lebih dalam pada generasi $\mathrm{X}$.

\section{SIMPULAN DAN SARAN}

Berdasarkan hasil penelitian yang diperoleh, maka dapat diambil beberapa kesimpulan sebagai berikut:

1. Terdapat perbedaan tingkat job embeddedness yang signifikan antara karyawan generasi X dan $\mathrm{Y}$ ditinjau dari budaya kolektivisme di PLTD Siantan, Kalimantan Barat.

2. Terdapat perbedaan job embeddedness yang signifikan antara karyawan generasi $\mathrm{X}$ dan generasi $Y$ di PLTD Siantan, Kalimantan Barat.

3. Terdapat perbedaan budaya kolektivisme yang signifikan antara karyawan generasi $\mathrm{X}$ dan generasi Y di PLTD Siantan, Kalimantan Barat.

4. Karyawan generasi $\mathrm{X}$ memiliki tingkat job embeddedness dan budaya kolektivisme yang lebih tinggi dibandingkan dengan karyawan generasi Y.

Berdasarkan hasil penelitian yang diperoleh, maka dapat dikemukakan beberapa saran sebagai berikut:

Kepada Pimpinan Perusahaan. Tingkat job embeddedness pada karyawan PLTD Siantan, Kalimantan Barat yang secara umum didominasi oleh karyawan generasi Y masih tergolong sedang. Hal ini dapat dijadikan bahan evaluasi perusahaan untuk dapat memberikan kegiatan guna meningkatkan job embeddedness karyawannya. Kegiatan yang dibuat seperti memberikan karyawan pekerjaan sesuai dengan bidang yang memang karyawan tersebut kuasai. Selain itu perusahaan juga dapat membuat kegiatan nonformal untuk melekatkan anggota kelompok seperti acara tahunan perusahaan, outbond, dan lain sebagainya. Perusahaan juga dapat melakukan promosi kenaikan jabatan, jenjang karir ataupun bonus yang ditujukan untuk meningkatkan keinginan karyawan untuk bertahan di perusahaan. Kegiatankegiatan yang disusun berdasarkan aspeknyaini akan meningkatkan job embeddedness karyawan pada perusahaan.

Kepada Karyawan. Saran yang dapat diberikan bagi karyawan generasi $\mathrm{X}$ maupun generasi $\mathrm{Y}$ di PLTD Siantan, Kalimantan Barat adalah menyadari karakteristik pribadi sesuai dengan diferensiasi berdasarkan generasi serta kultur kolektivisme dalam perusahaan. Setelah menyadari, maka karyawan dari kedua generasi tersebut diharapkan dapat berpartisipasi aktif dan mendukung program perusahaan dalam rangka meningkatkan job embeddedness karyawan.

Kepada Peneliti Selanjutnya. Saran untuk peneliti selanjutnya yang tertarik untuk melakukan penelitian di bidang atau pun tema yang sama adalah penelitian selanjutnya diharapkan dapat menambah jumlah responden agar mendapatkan gambaran yang lebih luas mengenai perbedaan job embeddedness pada kedua generasi. Penelitian selanjutnya juga dapat menggunakan atau menambahkan variabel lain, seperti wilayah tempat karyawan tinggal, komitmen organisasi, dan sebagainya. Selain itu, variasi juga dapat dilakukan oleh peneliti selanjutnya dalam pengambilan sampel, contohnya pengambilan sampel terkait perbedaan jenis kelamin karyawan. Peneliti juga berharap agar ke depannya, penelitian ini dapat digunakan sebagai bahan rujukan untuk melengkapi sumber pustaka penelitiannya.

\section{DAFTAR PUSTAKA}

Andrea, B., Gabriella, H.C., \& Tímea, J. (2016). $\mathrm{Y}$ and $\mathrm{Z}$ generations at workplaces. Journal of Competitiveness, 8(3), 90-106. 
Besich, J. (2005). Job embeddedness versus traditional models of voluntary turnover: A test of voluntary turnover prediction (Disertasi Doktor, University of North Texas). Diunduh dari https://digital.library. unt.edu/ark:/67531/metadc4977/

Bochner, S. (1994). Cross-cultural differencess in the self-concept. Journal of Cross Cultural Psychology, 25(2), 273-283.

Fatimah, H., Dharmawan, A. H., Sunarti E., \& Affandi, M. J. (2015). Pengaruh faktor karakteristik individu dan budaya organisasi terhadap keterikatan pegawai generasi X dan Y. Jurnal Aplikasi Manajemen, 13(3), 402-409.

Febriana, R. (2016). Pembagian unit induk PLN sesuai sistem tenaga listrik. Diunduh dari https://www.warriornux.com/pemb agian-unit-induk-pln-sesuai-sistemtenaga-listrik/

Fitriyani, W. (2013). Pengaruh kepribadian dan job embeddedness terhadap organizational citizenship behavior (OCB) pada karyawan PT. Hadji Kalla Makassar (Skripsi, Universitas Hasanuddin). Diunduh dari http://repository.unhas.ac.id/ handle/123456789/6011

Granovetter, M. (2010). Economic action and social structure: The problem of embeddedness. The American Journal of Sociology, 91(3), 481510.

Gursoy, D., Chi, C.Q. \& Karadag, E. (2013). Generational differences in work values and attitudes among frontline and service contact employees. International Journal of Hospitality Management, 32, 4048.

Hidayat, A. (2013). Uji normalitas. Diunduh dari https://www. statistikian.com/2013/02/ujinormalitas-pada-spss.html.

Hofstede, G., Hofstede, G.J., \& Minkov, M. (2010). Culture and organization: Software of mind. NY: McGrawHill.
Holtom, B.C., Mitchell, T.R., \& Lee, T.W. (2006). Increasing human and social capital by applying job embeddedness theory. Organizational Dynamics, 35(4), 316-331.

Karunia, E. (2015). Perbedaan intensi turnover berdasarkan kategori generasi karyawan. (Skripsi, Universitas Gadjah Mada). Diunduh dari http://etd.repository .ugm.ac.id/

Lancaster, L.M. (2004). When generation collide: How to solve generation puzzle at work. NY: HarperCollins.

Mitchell, T.R., Holtom, B.C., Lee, T.W., \& Erez, M. (2001). Why people stay: Using job embeddedness to predict voluntary turnover. Academy of Management Journal, 44(6), 11021121.

Nafei, W. (2015). The role of job embeddedness on quality of work life and organizational citizenship behavior: A study on Menoufia University Hospitals. International Journal of Business and Management, 10(4), 215- 231

Ng, T.W.H. \& Feldman, D.C. (2009). Occupational embeddedness and job performance. Journal of Organizational Behavior, 30, 863891.

Nguyen, V.Q. (2010). Organizational, job, and supervisory antecedents and consequence of job embeddedness: The case of Vietnam. (Disertasi, ProQuest Dissertations Publishing).

Oktariani, D., Hubeis, A.V.S. \& Sukandar, D. (2017). Kepuasan kerja generasi $\mathrm{X}$ dan generasi $\mathrm{Y}$ terhadap komitmen kerja di Bank Mandiri Palembang. Jurnal Aplikasi Bisnis dan Manajemen, 3(1), 12-22.

Pane, D. A. (2016). Pengaruh psychological well-being dan job embeddedness terhadap turnover intentions. (Tesis Magister, Universitas Sumatera Utara).

Pardinata, L., \& Respati, A. (2014). Perbedaan job embeddedness generasi $X$ dan $Y$. Diunduh dari 
http://lib.ui.ac.id/naskahringkas/201 6-06/S56254Lirmanto\% 20Pardina-

ta.

Sekretariat Kabinet. (2017). BPS: Jumlah penduduk bekerja naik 6,13 juta, pengangguran turun 0,28 persen. Diakses 16 November 2017, dari http://setkab.go.id/bps-jumlahpenduduk-bekerja-naik-613-jutapengangguran-turun-028-persen/

Septarini, B.G., \& Yuwono, I. (2003). Pengaruh budaya kolektivisme terhadap kompetensi inti pada kelompok lini manajerial PT Semen Gresik (Persero) Tbk. Insan Media Psikologi, 5(1), 1-14.

Qalbi, S. N., Jufri, M. dan Indahari, N. A. (2016). Pengaruh job embeddedness terhadap intensi turnover karyawan. Jurnal Psikologi Jambi, 1(1), 48-54.

Tolbize, A. (2016). Generational differencess in the workplace. Minesota: University of Minesota. Diunduh dari https://rtc.umn.edu/ docs/2_18_Gen_diff_workplace.pd $\mathrm{f}$

Xuyen, P.H., Utari, P., \& Rahmanto, A.N. (2016). Kolektivisme tercermin dalam iklan televisi Vietnam. Jurnal IKON, 2(4), 13-19. 